\title{
The effects of papaverine on the electrical
}

\section{and mechanical activity of the}

\section{guinea-pig taenia coli}

\author{
N. TASHIRO AND T. TOMITA
}

Department of Physiology, Kyushu University, Fukuoka, Japan

\section{Summary}

1. Effects of papaverine $\left(5 \times 10^{-6}-5 \times 10^{-5} \mathrm{M}\right)$ were studied on the spontaneous and evoked electrical and mechanical activity of the guinea-pig taenia coli. In normal Locke solution, papaverine slowed and finally stopped the spontaneous spike discharge, usually with a small hyperpolarization of a few $\mathrm{mV}$.

2. Papaverine did not change the membrane resistance in normal Locke solution. It abolished the repetitive firing of spikes during the depolarization in response to a current pulse, but a single spike of normal amplitude could always be evoked.

3. The mechanical response elicited by a single spike was reduced by papaverine in normal Locke solution. During the maintained depolarization produced by a long current pulse the tonic component of the contraction was more reduced than the phasic component related to the initial spike activity.

4. The effects of papaverine were essentially the same as in normal Locke solution when $\mathrm{NaCl}$ was replaced with $\mathrm{LiCl}$, or in excess $\mathrm{K}(24 \mathrm{~mm})$, except that the membrane resistance was increased by papaverine in the presence of excess $\mathbf{K}$.

5. Excess $\mathrm{Ca}(6 \mathrm{mM})$ antagonized the effect of papaverine on the mechanical response, but not on the electrical response. When the muscle was depolarized in Ca-free solution, papaverine caused repolarization of the membrane and electrical activity reappeared. This effect was similar to that of $\mathrm{Mg}$ (4 mM).

6. The mechanism by which papaverine suppresses the spontaneous spike activity is discussed and is compared with that of isoprenaline, from which it appears to differ. The observations indicate that papaverine, like $\mathbf{M g}$, may bind with a site at the membrane with which $\mathrm{Ca}$ normally binds, thereby modifying the electrical and mechanical activity controlled by $\mathrm{Ca}$.

\section{Introduction}

Papaverine is known to suppress the spontaneous electrical and mechanical activity of the guinea-pig taenia coli in normal physiological solutions. Its mode of action, however, has been studied chiefly on the contracture produced by potassium or by acetylcholine. The suppression of the tonic component of the contracture is much larger than that of the initial phasic component (Imai \& Takeda, 1967 ; Ferrari \& Carpenedo, 1968). Since it is believed that the phasic component results from the spike activity which is produced by an inward movement of calcium 
ions across the membrane, and that the tonic component is caused by the release of calcium from the membrane, it has been postulated that the action of papaverine is due to a reduction of the "bound calcium" at the membrane.

In the present experiments, the effect of papaverine was further investigated by studying the electrical and mechanical responses evoked by electrical stimulation. The method was the same as that used recently for an investigation of the inhibitory action of catecholamines on the electrical activity of the taenia coli (Bülbring \& Tomita, 1969a, b). This showed that the block of spike activity by adrenaline is mainly associated with hyperpolarization and an increased membrane conductance, while isoprenaline suppresses the spontaneous activity with little change in membrane conductance. The effect of papaverine resembles that of isoprenaline. A comparison of papaverine with isoprenaline is therefore of interest.

\section{Methods}

A thin strip (diameter $<1 \mathrm{~mm}$ ) of about $30 \mathrm{~mm}$ length was dissected from the guinea-pig taenia coli and mounted in a double sucrose-gap apparatus. The method was essentially the same as that used by Bülbring \& Tomita (1969a). Only the small centre part $(c a .1 .5 \mathrm{~mm})$ of the piece of taenia was exposed to the test solution, both ends of the tissue being in isotonic sucrose solution for stimulation and recording, respectively. A detailed analysis of the responses obtained by this method has recently been reported (Kuriyama \& Tomita, 1970), in which it was shown that a change in the size of electrotonic potential indicates a change in the membrane resistance. Spontaneous activity was sometimes absent, especially when the sucrose flowed comparatively fast. This weak spontaneous activity may be the result of a low resting tension, and of the hyperpolarization of the membrane in the small piece of tissue caused by diluting the Locke solution, on both sides, with sucrose solution.

In a few experiments, intracellular electrical recordings were made by the conventional method (see Abe \& Tomita, 1968).

In all experiments, Locke solution was used as the normal physiological solution and the temperature was $35^{\circ} \mathrm{C}$. In some experiments the ionic composition of Locke solution was altered in order to investigate the papaverine effect in different media. Papaverine hydrochloride was obtained from Merck.

Results

\section{Effect of papaverine in normal Locke solution}

\section{Intracellular recordings}

Figure 1 shows examples of papaverine effects obtained by intracellular recordings. When papaverine $\left(10^{-5} \mathrm{M}\right)$ was applied, the spike frequency of spontaneous spike discharge was gradually reduced without change in membrane potential or spike amplitude (b, $\mathrm{c}$ and e). The spontaneous activity finally stopped after about $10 \mathrm{~min}$. This slow effect was mainly due to the gradual increase of the papaverine concentration in the recording chamber. When all activity stopped the membrane potential was often slightly higher than the control by a few $\mathrm{mV}$. The tension also gradually declined. Just before the spontaneous activity ceased, the interval between 
spikes and the amplitude of the spikes became irregular (c and e). However, spikes with nearly the normal configuration occasionally appeared spontaneously, or could be evoked by electrical stimulation.

The effect was reversible. When papaverine was removed the spontaneous activity and tension response gradually recovered within about $10 \mathrm{~min}$. However, the recovery was slower after long exposures $(>30 \mathrm{~min})$ or when the concentration was high $\left(10^{-4} \mathrm{M}\right)$. It was difficult to keep the intracellular microelectrode in the same cell for a long time, so most studies were carried out by the double sucrose-gap method.

\section{Double sucrose-gap recordings}

With the double sucrose-gap method, the change in the solution was completed within $1 \mathrm{~min}$. Papaverine $\left(10^{-5} \mathrm{M}\right)$ blocked the spontaneous and anode-break

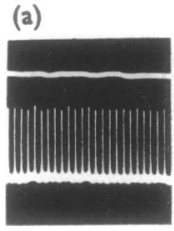

(b)

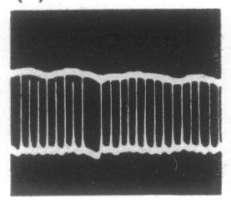

(d)

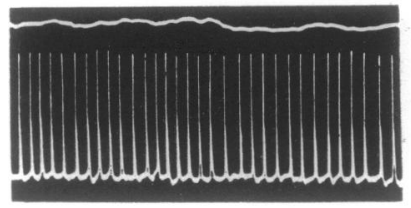

(c)

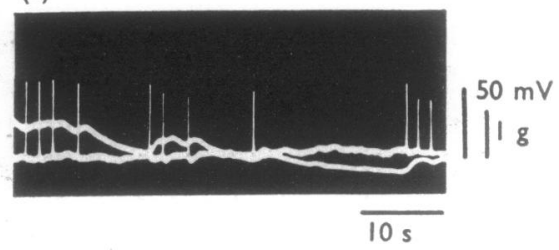

(e)

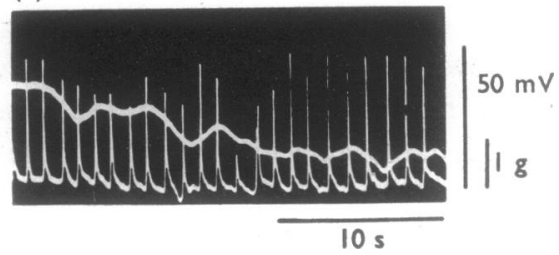

FIG. 1. Intracellular recordings from two different preparations of guinea-pig taenia coli (a-c and d, e). (a) and (d), Control; (b), $5 \mathrm{~min}$, (c), $10 \mathrm{~min}$, (e), $8 \mathrm{~min}$ after papaverine $\left(10^{-5} \mathrm{M}\right)$ application. Note reduction of spike frequency and tension by papaverine.

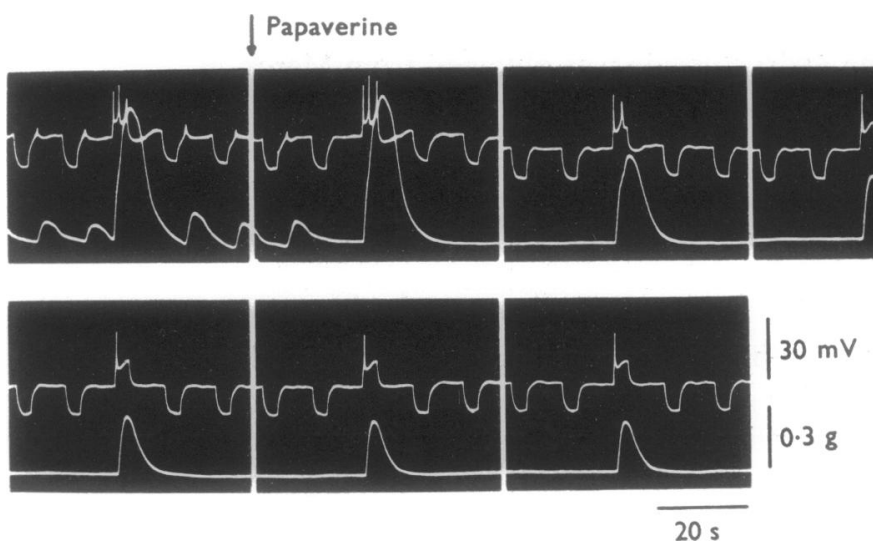

FIG. 2. Electrical (upper trace) and mechanical responses (lower trace) recorded by the double sucrose gap method. In each frame, the responses to four hyperpolarizing current pulses and one depolarizing pulse are shown (pulse duration $3 \mathrm{~s}$ ). Top left-hand, Control. Records taken every minute after papaverine $\left(10^{-5} \mathrm{M}\right)$ application. 
response within $1 \mathrm{~min}$. However, a spike could always be evoked in response to electrical stimulation, as previously reported (Imai \& Takeda, 1967). The membrane was often slightly hyperpolarized. The amplitude of electrotonic potentials usually remained the same, but in some preparations a small increase in the amplitude was observed. The number of spikes during the depolarization gradually decreased and, finally, no repetitive firing of action potentials could be produced, although a single spike of normal amplitude always appeared, as shown in Fig. 2. The tension was also reduced, and the decrease in the tension proceeded further even after the repetitive firing had stopped.

It has been shown (Bülbring \& Tomita, 1969a, b) that the block of spontaneous and evoked spikes by adrenaline is associated with clear hyperpolarization and a decrease in the electrotonic potential. On the other hand, isoprenaline blocks spontaneous spike activity with little hyperpolarization and with little reduction of

(a)
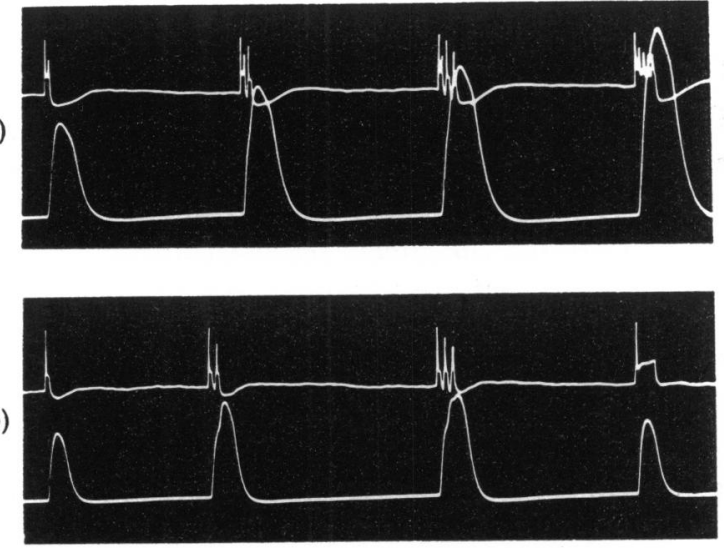

(b)
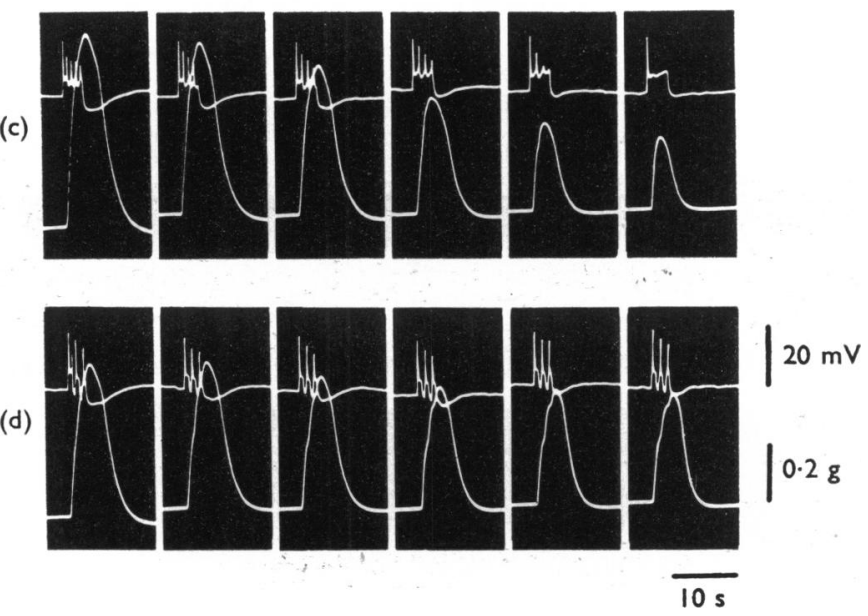

FIG. 3. Electrical (upper trace) and mechanical (lower trace) responses to single, double or triple stimuli of $600 \mathrm{~ms}$ pulses at $400 \mathrm{~ms}$ interval, and to a long pulse of $3 \mathrm{~s}$ duration. (a), Control; (b), responses to the same stimuli $10 \mathrm{~min}$ after papaverine $\left(10^{-5} \mathrm{M}\right)$; (c), responses evoked by a $3 \mathrm{~s}$ pulse; (d), responses to three $600 \mathrm{~ms}$ pulses with $400 \mathrm{~ms}$ interval, recorded at $1 \mathrm{~min}$ intervals after papaverine $\left(10^{-5} \mathrm{M}\right)$ application. 
the electrotonic potential. The effect of papaverine appears to be similar to that of isoprenaline in the mode of action.

During the recovery from papaverine, spontaneous activity usually reappeared within $1 \mathrm{~min}$, but the number of repetitive spikes evoked by depolarization increased more gradually and returned to normal only after more than $5 \mathrm{~min}$. The recovery of tension was even slower and took about $10 \mathrm{~min}$.

Since papaverine stopped the repetitive firing but did not suppress the generation of a single spike, the mechanical response was differently affected according to and depending on the stimulus parameters. Figure $3 \mathrm{a}$ shows, from left to right, responses to single, double, and triple stimuli $(600 \mathrm{~ms}$ pulse duration and $400 \mathrm{~ms}$ interval), and to a long pulse ( $3 \mathrm{~s})$ of the same intensity in normal Locke solution. When papaverine $\left(10^{-5} \mathrm{M}\right)$ was applied (b), the tension response to the long current pulse of $3 \mathrm{~s}$ duration (right-hand side) was most dramatically reduced but that to the short pulses not so much. Records shown in Fig. 3c are the responses to a long current pulse ( $3 \mathrm{~s}$ duration) taken at $1 \mathrm{~min}$ intervals after papaverine $\left(10^{-5} \mathrm{M}\right)$ application (left to right) and in (d) the responses to three short pulses $(600 \mathrm{~ms}$ duration) are shown. The reduction of the tension by papaverine was slower when repetitive stimulation with short pulses was applied than a single stimulation with a long pulse, which produced repetitive spikes in normal solution.

When the membrane was depolarized by a very long current pulse (30 s), the tension development had two phases, a phasic component related to the spike, and a tonic component related to the sustained depolarization. Papaverine mainly suppressed the tonic response, so that after about 5 min only the phasic component remained (Fig. 4).

\section{Excess potassium (24 mM)}

It is interesting to study the effect of papaverine in excess potassium solution and in low sodium solution in which sodium is replaced with lithium, because in both solutions the block of spontaneous spike activity by isoprenaline becomes very weak (Bülbring \& Tomita, 1969b). In the presence of a high external potassium concen-

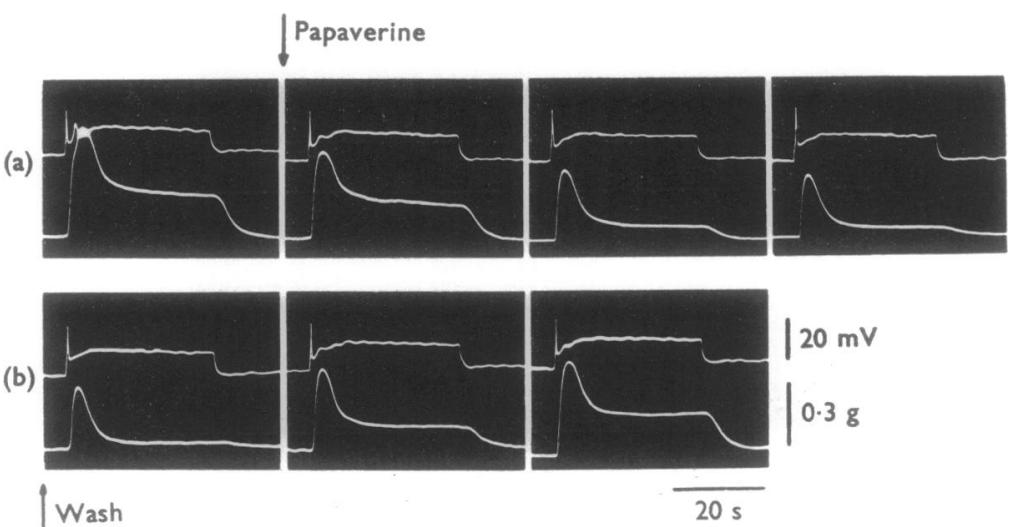

FIG. 4. Responses to depolarizing current of $30 \mathrm{~s}$ duration. Upper trace, Membrane potential ; lower trace, tension. (a), Effect of papaverine $\left(5 \times 10^{-5} \mathrm{M}\right)$ recorded at 1 min intervals ; (b), recovery from the papaverine effect recorded at $1 \mathrm{~min}$ intervals. Note that the sustained tonic contraction is more reduced by papaverine than the phasic contraction. 
tration, the effect of papaverine was essentially the same as in normal Locke solution, except that, in excess potassium, the amplitude of the electrotonic potential was clearly increased by papaverine, as shown in Fig. 5.

It has been reported by Kuriyama \& Tomita (1970) that the electrotonic potential observed by the double sucrose-gap method is closely correlated with a change of the transmembrane potential recorded intracellularly. The result shown in Fig. 5 therefore suggests that papaverine increased the membrane resistance in excess potassium solution.

\section{Low sodium (replacement with lithium)}

When the $\mathrm{NaCl}$ of the Locke solution was substituted by $\mathrm{LiCl}$, spontaneous activity of high frequency appeared after a transient quiescent period (usually about $10 \mathrm{~min}$ ), but the mechanical response became small, as previously observed (Axelsson, 1961 ; Bülbring \& Kuriyama, 1963 ; Bülbring \& Tomita, 1969b). In this condition, the effect of papaverine was essentially the same as in normal Locke solution, as shown in Fig. 6. The spontaneous activity was suppressed without an accompanying hyperpolarization of the membrane, and the number of spikes during the depolarizing current application was reduced to one.

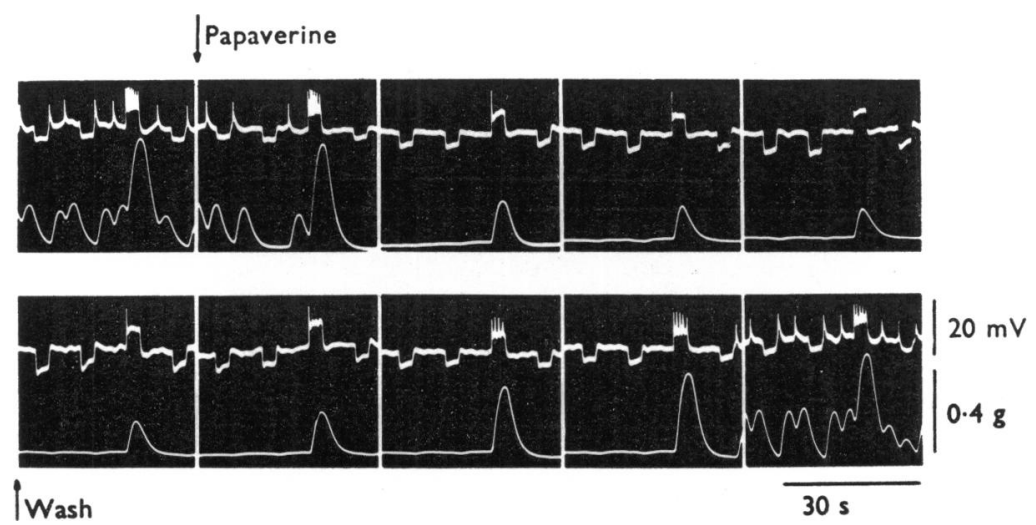

FIG. 5. Papaverine effect $\left(10^{-5} \mathrm{M}\right)$ in the presence of excess $\mathrm{K}(24 \mathrm{mM})$ recorded at $1 \mathrm{~min}$ intervals on electrical (upper trace) and mechanical responses (lower trace). Top, Papaverine application between first and second record ; bottom, recovery from papaverine. Note suppression of spontaneous spike, decrease in repetitive spike activity during depolarization, increase in electrotonic potential, and decrease in tension by papaverine.

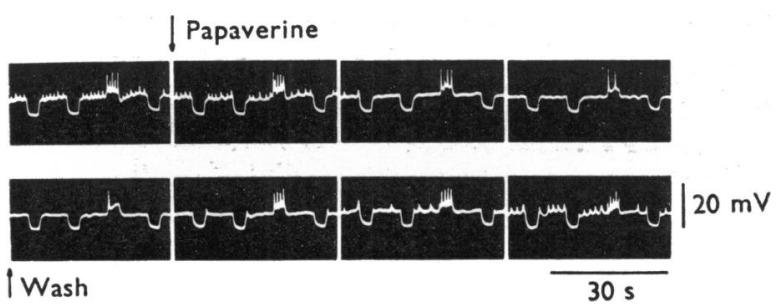

FIG. 6. Papaverine $\left(10^{-5} \mathrm{M}\right)$ effect in $\mathrm{Li}$ solution $(\mathrm{NaCl}$ was replaced by $\mathrm{LiCl})$ on electrical responses of taenia coli. Top, Papaverine applied between first and second record; bottom, recovery from papaverine, taken at $40 \mathrm{~s}$ intervals. 


\section{Excess calcium (6 $\mathrm{mM})$}

It has been shown previously that, in the depolarized taenia coli of the guinea-pig, the effects of papaverine on the potassium contracture are antagonized by increasing the calcium concentration in the external solution (Ferrari \& Carpenedo, 1968). In the experiment shown in Fig. 7, the preparation was in normal solution and was first (Fig. 7a) exposed to papaverine $\left(5 \times 10^{-5} \mathrm{M}\right)$ for about $10 \mathrm{~min}$. This reduced the tension. Then (Fig. $7 b$ ) the external calcium concentration was increased from $2 \mathrm{mM}$ to $6 \mathrm{mM}$. The tension increased gradually without a significant change in the electrical response. When the tension was increased by excess calcium, the duration of tension response remained more or less the same, although papaverine reduced the tension amplitude as well as its duration.

\section{Calcium-free Locke solution}

When calcium was removed from the external solution, the membrane was depolarized, the membrane resistance became very low, and the electrical and mechanical activity nearly disappeared (Brading, Bülbring \& Tomita, 1969a, b ; Bülbring \& Tomita, 1970a, b). When papaverine was added to the calcium-free solution after the effect of calcium-lack was fully developed, the membrane was gradually repolarized and some electrical activity developed (Fig. 8). This electrical

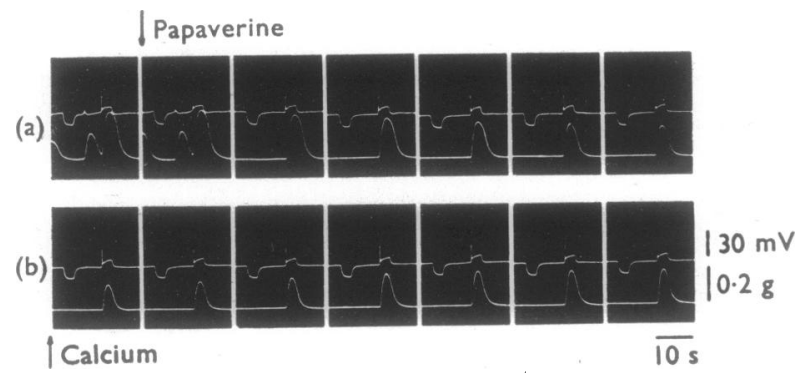

FIG. 7. Effect of excess $\mathrm{Ca}(6 \mathrm{mM})$ on the action of papaverine $\left(5 \times 10^{-5} \mathrm{M}\right)$ on electrical (upper trace) and mechanical responses (lower trace). (a), Papaverine given between first and second record, effect recorded at $1 \mathrm{~min}$ intervals ; (b), after about $10 \mathrm{~min}$ papaverine application $\mathrm{Ca}$ was increased from 2 to $6 \mathrm{~mm}$, effect recorded at $1 \mathrm{~min}$ intervals. Note increase in mechanical response.
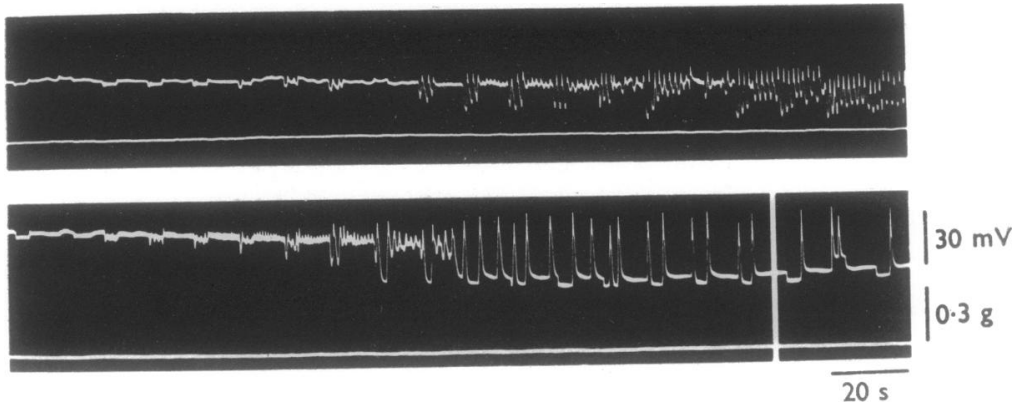

FIG. 8. Effect of papaverine $\left(10^{-5} \mathrm{M}\right)$ in Ca-free Locke solution (Ca omitted, $0 \cdot 1 \mathrm{mM}$ EGTA (ethyleneglycol-bis ( $\beta$-aminoethyl ether)-N, $N^{\prime}$-tetra-acetic acid) added) on electrical activity of taenia coli in two different preparations. Papaverine was applied at the beginning of both records. The last section of the lower record was taken after a 2 min interval. 
activity depended on the presence of sodium in the external solution. It was very similar to that produced by addition of $0.5 \mathrm{~mm}$ magnesium in calcium-free solution (Bülbring \& Tomita, 1970a, b).

\section{Excess magnesium (4. $\mathrm{mM})$}

There were apparent similarities between the effects of magnesium and papaverine. Both stopped the spontaneous activity, both suppressed the repetitive firing during depolarization of the membrane, and both diminished the tension response. However, there were some differences. The effect of magnesium reached a steady state faster than that of papaverine (Fig. 9), both in developing (a, b) and during recovery (c, d).

When the effect of magnesium and papaverine was fully developed, a stimulating current pulse was applied during a long conditioning depolarization (about $10 \mathrm{~s}$ duration). If the reduction of the response was simply due to an increase in the threshold, the conditioning depolarization should produce a recovery of the response. The conditioning depolarization increased the tension response in the preparation

(a)
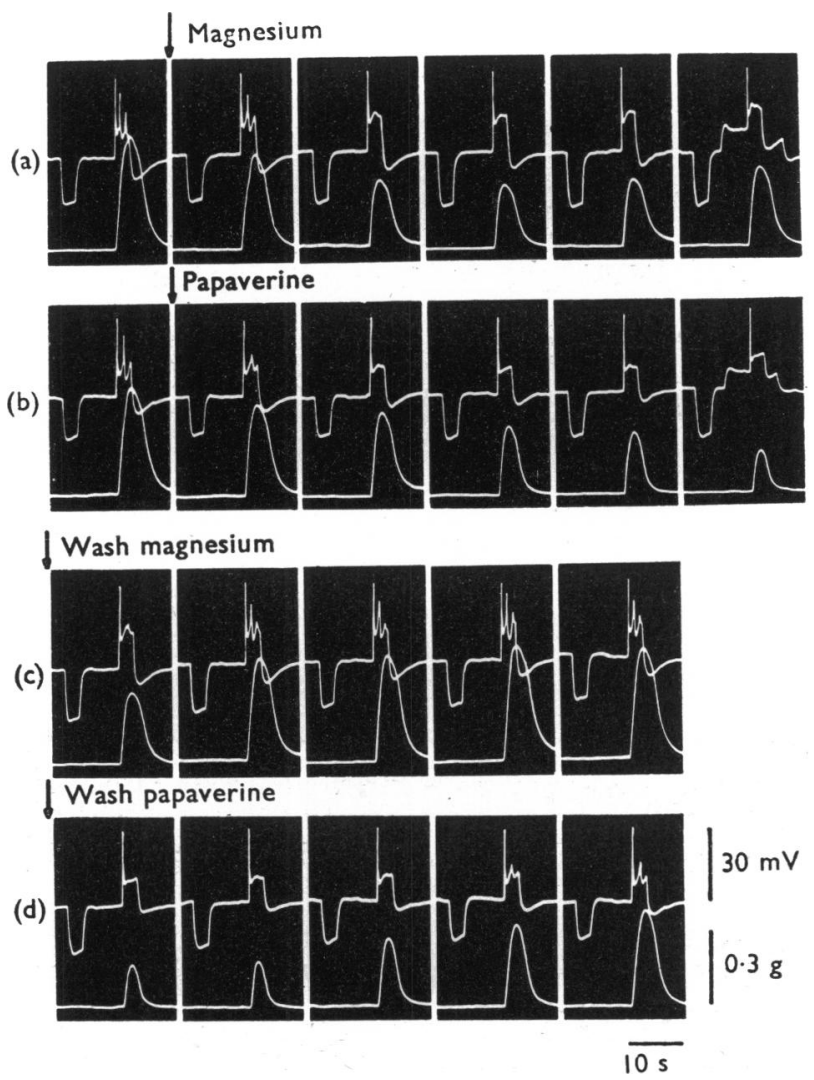

FIG. 9. Effect of magnesium (4 mM) (a and c); and of papaverine $\left(5 \times 10^{-5} \mathrm{M}\right)(\mathrm{b}$ and $\mathrm{d})$, applied after recovery from magnesium on electrical (upper trace) and mechanical responses (lower trace). Records taken at $1 \mathrm{~min}$ intervals. Last record on the right in (a) and (b) shows effect of conditioning depolarization ; (c) and (d), recovery process. (c) is continuation of (a), and (d) continuation of (b). Note similarity between magnesium and papaverine, but slower onset of, and recovery from, papaverine effect. 
treated with magnesium (last record on the right in Fig. 9a and Fig. 10a), but it had no effect in the preparation treated with papaverine (last record on the right in Fig. $9 \mathrm{~b}$ and Fig. 10b).

The tension was further suppressed by applying papaverine after the magnesium effect was fully developed (Fig. 10). The duration of the tension response became shorter (Fig. 10b) with papaverine, and the recovery of the duration of the response was slower than of the amplitude of the tension (Fig. 10c).

\section{Discussion}

The decrease in the mechanical response caused by papaverine in normal solution is the result of several effects: the suppression of spontaneous spike activity, the reduction in the number of spikes evoked by a depolarizing pulse, and a partial block of the excitation-contraction coupling.

During prolonged depolarization of the membrane, the excitation-contraction coupling of the tonic component (contracture) seems to be more affected than the

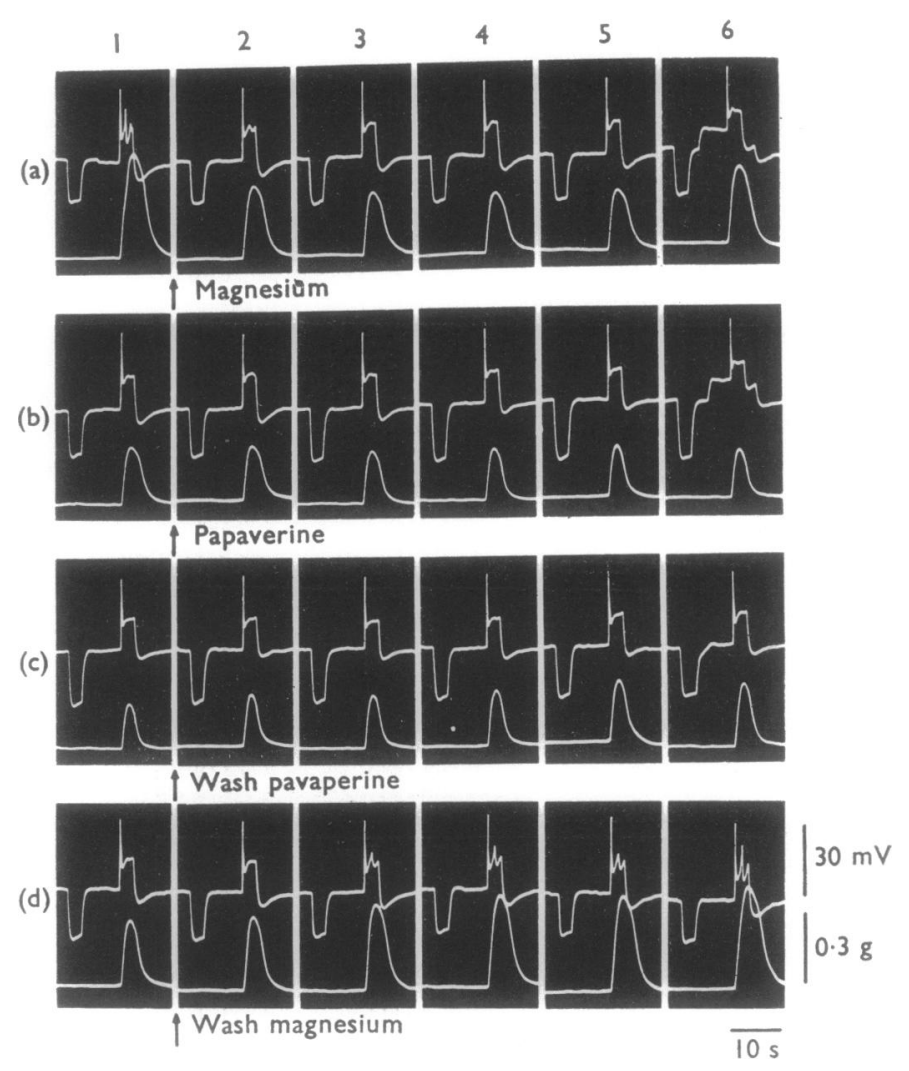

FIG. 10. Effect of papaverine in the presence of magnesium on electrical (upper trace) and mechanical responses (lower trace). (a1), Control in normal solution ; (a2-6), effect of magnesium (4 mM) taken at 1 min intervals; (a6), conditioning depolarization applied. (b), In the presence of magnesium $(4 \mathrm{mM})$, effect of papaverine $\left(5 \times 10^{-5} \mathrm{M}\right)(\mathrm{b} 2-6) ;(\mathrm{b} 6)$, conditioning depolarization applied. (c2-6), Papaverine washed out but magnesium still present. (d2-6), Magnesium washed out, recovery in normal Locke solution. The intervals between rows of records were 2 or 3 min. 
coupling of the phasic contraction initiated by the spike. This has also been demonstrated for the contracture produced by high potassium (Imai \& Takeda, 1967 ; Ferrari \& Carpenedo, 1968). The selective suppression of the tonic phase of the contracture may be related to the fact the papaverine reduces oxidative phosphorylation (Ferrari \& Carpenedo, 1968 ; Santi, Ferrari \& Contessa, 1964). It is known that the tonic phase is very susceptible to metabolic inhibitors, anoxia, and glucose deprivation (Born, 1956 ; Axelsson, Högberg \& Timms, 1965 ; Pfaffman, Urakawa \& Holland, 1965), while the spike activity is increased by these treatments (Axelsson \& Bülbring, 1961 ; Axelsson, Högberg \& Timms, 1965). The suppression of spontaneous spike activity by papaverine is therefore probably not the result of metabolic inhibition.

The abolition of the spontaneous spike discharge may not be due simply to hyperpolarization of the membrane, but probably to a direct action of papaverine on the pace-maker mechanism, like the action of isoprenaline, since the suppression can be seen in some preparations without clear hyperpolarization, as shown in Fig. 1. This is quite different from the action of adrenaline, which produces clear hyperpolarization and an increase of membrane conductance (Bülbring \& Tomita, $1969 \mathrm{a}, \mathrm{b})$. The suppression of the spontaneous activity may be related to the suppression of the repetitive firing of the spike during depolarization of the membrane by a long current pulse. This suppression is not overcome by conditioning depolarization (see Figs. 9 and 10). The result also suggests that hyperpolarization of the membrane is not a main cause in reducing the activity. The slight hyperpolarization seen in some preparations may result merely from the disappearance of the spontaneous activity in the presence of papaverine. Diamond \& Marshall (1969) have observed that in the rabbit myometrium papaverine suppressed the spontaneous spikes without any change in the membrane potential.

The effect of papaverine is similar to that of isoprenaline in suppressing the spontaneous spike activity of taenia coli with little change in the membrane potential or in conductance (Bülbring \& Tomita, 1969b). However, the underlying mechanism of the action of papaverine is probably different from that of isoprenaline: The effect of papaverine is not influenced by propranolol (unpublished observation), which blocks the effect of isoprenaline. Furthermore, the effect of isoprenaline becomes very weak when the external potassium concentration is increased to $24 \mathrm{~mm}$, or when $\mathrm{NaCl}$ is replaced by $\mathrm{LiCl}$, while papaverine still blocks the spontaneous spikes in these solutions. Another difference between isoprenaline and papaverine is that repetitive spikes can be produced by a long current pulse in the presence of isoprenaline (Bülbring \& Tomita, 1969b) but not in the presence of papaverine. The abolition of repetitive firing may not simply be due to a prolongation of the refractory period, because, when a short current pulse is used for stimulation, the spike can be evoked by a second stimulus applied within a short interval, as shown in Fig. 3.

Some of the action of papaverine can probably be explained by assuming that papaverine occupies membrane sites where calcium normally binds (Imai \& Takeda, 1967). The calcium bound at these sites may be involved in controlling the ion permeability of the membrane, in the generation of the pace-maker potential and in the contraction. Also magnesium seems to bind with these membrane sites (Bülbring \& Tomita, 1970a, b ; Kuriyama \& Tomita, 1970) and it suppresses both the pace-maker potential and the contraction. When calcium ions are present, 
papaverine may compete with calcium for these sites in the same way as magnesium, reducing the pace-maker potential and the contraction and, when the external solution contains no calcium, papaverine may again act like magnesium, reducing the membrane permeability to other ions. The question as to whether there are different membrane sites for every particular function of calcium remains to be answered.

We thank Professor E. Bülbring for her help and comments in preparing the manuscript.

\section{REFERENCES}

AвE, Y. \& Tомтта, T. (1968). Cable properties of smooth muscle. J. Physiol., Lond., 196, 87-100. Axelsson, J. (1961). Dissociation of electrical and mechanical activity in smooth muscle. J. Physiol., Lond., 158, 381-398.

Axelsson, J. \& Bülbring, E. (1961). Metabolic factors affecting the electrical activity of intestinal smooth muscle. J. Physiol., Lond., 156, 344-356.

Axelsson, J., Högberg, S. G. R. \& Timms, A. R. (1965). The effect of removing the readmitting glucose and glycogen content of intestinal smooth muscle from the taenia coli of the guinea-pig. Acta physiol. scand., 64, 28-42.

BORN, G. V. R. (1956). The relation between the tension and the high-energy phosphate content of smooth muscle. J. Physiol., Lond., 131, 704-711.

Brading, A., Bülbring, E. \& Tomita, T. (1969a). The effect of temperature on the membrane conductance of the smooth muscle of the guinea-pig taenia coli. J. Physiol., Lond., 200, 621-635.

Brading, A., Bülbring, E. \& Tomita, T. (1969b). The effect of sodium and calcium on the action potential of the smooth muscle of the guinea-pig taenia coli. J. Physiol., Lond., 200, 637-654.

BülbBRING, E. \& KURIYAMA, H. (1963). Effects of changes in the external sodium and calcium concentrations on spontaneous electrical activity in smooth muscle of guinea-pig taenia coli. $J$. Physiol., Lond., 166, 29-58.

BÜlbRING, E. \& TOMITA, T. (1969a). Increase of membrane conductance by adrenaline in the smooth muscle of guinea-pig taenia coli. Proc. R. Soc. B., 172, 89-102.

Bülbring, E. \& TOMITA, T. (1969b). Suspension of spontaneous spike generation by catecholamines in the smooth muscle of the guinea-pig taenia coli. Proc. $R$. Soc. B., 172, 103-119.

BÜlbring, E. \& Tomita, T. (1970a). Calcium and the action potential in smooth muscle. In Calcium and Cellular Function, ed. Cuthbert, A. W., pp. 249-260. London: Macmillan.

Bülbring, E. \& Tomita, T. (1970b). Effect of Ca removal on the smooth muscle of the guinea-pig taenia coli. J. Physiol., Lond., in the Press.

Diamond, J. \& Marshall, J. M. (1969). Smooth muscle relaxants: Dissociation between resting membrane potential and resting tension in rat myometrium. J. Pharmac., 168, 13-20.

FerRARI, M. \& CARPENEDO, F. (1968). On the mechanism of action of some myolytic agents on depolarized guinea-pig taenia coli. Archs int. Pharmacodyn. Thér., 174, 223-232.

IMAI, S. \& TAKEDA, K. (1967). Effect of vasodilators upon the isolated taenia coli of the guinea-pig. J. Pharmac., 156, 557-564.

KurIYAMA, H. \& Tomita, T. (1970). The action potential in the smooth muscle of the guinea-pig taenia coli and ureter studied by the double sucrose-gap method. J. gen. Physiol., 55, 147-162.

Pfaffman, M., Urakawa, N. \& Holland, W. C. (1965). Role of metabolism in K-induced tension changes in guinea-pig taenia coli. Am. J. Physiol., 208, 120-1205.

Santi, R., Ferrari, M. \& Contessa, A. R. (1964). On the mechanism of spasmolytic effect of papaverine and certain derivatives. Biochem. Pharmac., 13, 153-158.

(Received February 10, 1970) 